\title{
Footwork technique used in elite table tennis matches
}

\author{
Ivan Malagoli Lanzoni', Michail Katsikadelis², Gunter Straub³ and Zoran Djokić4 \\ I Department for Life Quality Studies, University of Bologna, Italy \\ ${ }^{2}$ School of Physical Education and Sport Science, University of Thrace, Greece \\ ${ }^{3}$ Association of German Table Tennis Coaches, Germany \\ ${ }^{4}$ Faculty of Sport and Tourism, University EDUCONS, Novi Sad, Serbia
}

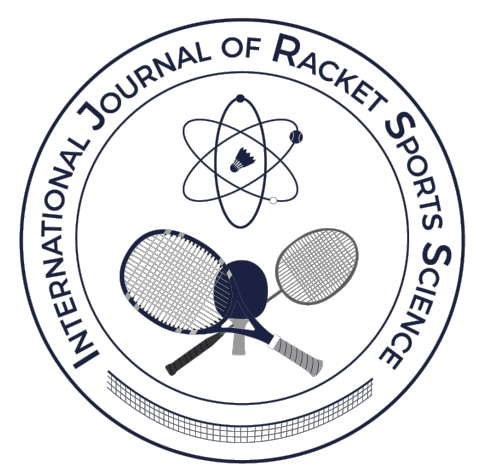

\begin{abstract}
Notational and Match analysis are very well-recognized methods to collect information about the most common technical-tactical performance indicators in table tennis: footwork and stroke types. The aim of this study was to compare footwork distributions in men (M) and women (W) elite table tennis competitions. Nine men's and nine women's matches were analyzed. All players were in the top $120(\mathrm{M})$ and $111(\mathrm{~W})$ positions of the ITTF world ranking. An expert coach analyzed game video recordings in slow motion with the software Kinovea and collected data about the footwork types used by the players during the games. The results showed differences between $\mathrm{M}$ and $\mathrm{W}: \mathrm{M}$ prefer to use one step $(35.6 \%, \mathrm{~W}: 21.9 \%), \mathrm{W}$ prefer to hit the ball without performing any step (W: $40.2 \%, \mathrm{M}: 20.4 \%$ ), the chassé is equally used (M: $19.7 \%, \mathrm{~W}: 21.7 \%$ ), and the crossover is mainly used by $\mathrm{M}$ $(11.1 \%, \mathrm{~W}: 3.7 \%)$. The pivot is mainly used by M (9.9\%, W: $7.8 \%)$, and W prefer the slide (4.9\%, M: $3.2 \%)$. In conclusion, this study can be useful for physical trainers, performance analysts, and coaches, to design specific footwork training sessions for $\mathrm{M}$ and $\mathrm{W}$ elite table tennis players.
\end{abstract}

Keywords: Racket sports, Match Analysis, Notational Analysis, Footwork

Correspondence author: Ivan Malagoli Lanzoni

E-mail: ivan.malagoli@unibo.it

Cite this article as:

Malagoli Lanzoni, I., Katsikadelis, M., Straub, G., \& Djokic, Z. (2019). Footwork technique used in elite table tennis matches. International Journal of Racket Sports Science, 1(2), 44-48. 


\section{Introduction}

Table tennis is one of the most popular and played racket sports in the world and has been included in the Olympic programme since 1988. Technical and tactical skills are very well recognised as the most important performance factors in table tennis. They could be evaluated using notational analysis in order to collect and summarise sport-specific performance indicators (Hughes, 1998; Hughes \& Barlett, 2002). Stroke types were examined comparing different table tennis groups or individual players (Djokic, 2002; Drianovsky \& Otcheva, 2002; Zhang et al., 2014; Malagoli Lanzoni et al., 2014).

Another crucial aspect of the specific technique is the footwork performed before hitting the ball, as using a proper footwork technique allows the athletes to be in the best position for an effective shot (Malagoli Lanzoni et al., 2007).

Fuchs et al. (2018) reviewed all the literature about match analysis in table tennis, including a dedicated paragraph about footwork analysis and its development. In 2003, Tepper presented a basic classification of the main steps used by table tennis players. In 2007, Malagoli Lanzoni et al. suggested a standard definition of the different types of steps used by the athletes: one step, short steps (chassé, slide, turn/pivot), crossover, and "stroke without step". Malagoli Lanzoni et al. (2007) collected data about four top-class table tennis players, showing that the most frequent steps are: one step (37.3\%), turn/pivot (21.1\%), chassé (15.2\%), stroke without step (11.5\%), slide $(7.5 \%)$, and crossover (7.3\%). In 2009, Malagoli Lanzoni and Lobietti compared footwork techniques used by two groups of international and national players. Footwork analysis continued to evaluate different kinds of steps in relationship with other variables: shots and outcome of the rallies (Malagoli Lanzoni et al., 2010), and different group of players (Malagoli Lanzoni et al., 2013a, b, 2014).

To improve footwork technique, coaches use a large variety of exercises focused on a similar distribution of steps, for men and women, respectively, not clearly distinguishing training sessions.
The purpose of this study was to compare footwork distributions in men (M) and women (W) elite table tennis competitions.

\section{Methods}

Nine $\mathrm{M}$ and nine $\mathrm{W}$ matches were randomly selected, and one match per player was taken into account. The 18 male players were in the first 120 positions of the ITTF official World Ranking, whereas the 18 female players were in the first 111 positions when the matches were played.

All players adopted an offensive playing style because they did not use long-pimple rubbers, the typical rubbers used by defenders, and they were not using a backhand chop stroke when playing far from the table.

All the players were rigth-handed, considering the hand used to hold the racquet.

The mean \pm SD age, height, and body mass were $29.8 \pm 4.7$ years, $179.5 \pm 6.9 \mathrm{~cm}, 73.5 \pm 5.8 \mathrm{~kg}$ for males, and $24.3 \pm 3.7$ years, $162.9 \pm 6.3 \mathrm{~cm}, 55.0 \pm$ $5.0 \mathrm{~kg}$ for females.

The selected matches were played in the Olympic Games, Team World Championships, ITTF Pro Tour Circuit, ITTF World Cup, and Pro Tour Grand Finals.

The matches were downloaded from the official websites www.ittf.com and www.ettu.org. Each match was analyzed in slow motion ( 0.2 recorded speed) with the software Kinovea (www.kinovea.org).

Data collection was carried out through a Visual Basic-based application to create a data base directly in the Microsoft Excel software. An experienced table tennis coach collected the data about the footwork technique used during the matches. Krippendorff's alpha (Krippendorff, 2004) was calculated to evaluate intra-observer reliability. Alpha value can range between -1 and 1 , and 1 indicates perfect agreement. For footwork type, alpha value was 0.99. Previous studies showed a very good intra- and inter-observer reliability of footwork types using the present classification and methods (Malagoli Lanzoni et al., 2012; 2014).

The statistical analysis was performed with the SPSS statistical software, performing one way ANOVA with significance indicated as $\mathrm{p} \leq 0.05^{*}, \mathrm{p} \leq 0.01^{* *}$. 
The classification of footworks included the following categories (Malagoli Lanzoni et al., 2007): one step (Fig. 1), chassé step (Fig. 2), slide step (Fig. 3), crossover (Fig. 4), pivot step (Fig. 5), and shot without step (Fig. 6).

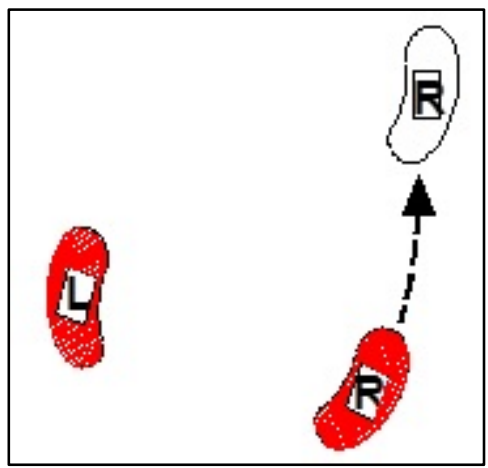

Figure 1. One step

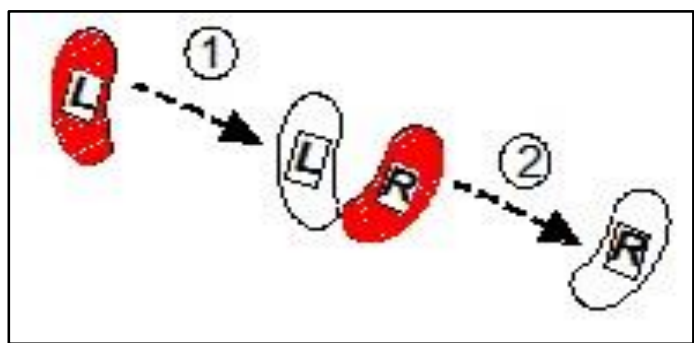

Figure 2. Chassé step

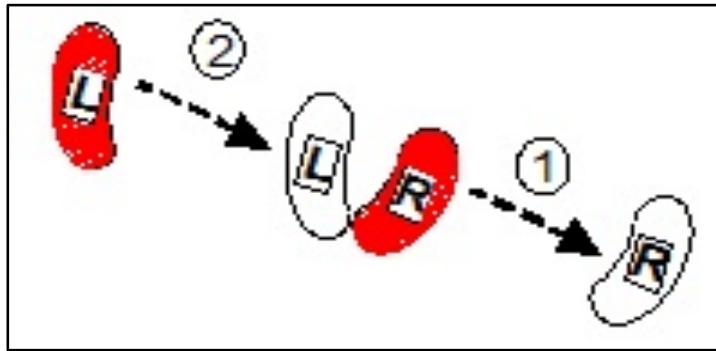

Figure 3. Slide step

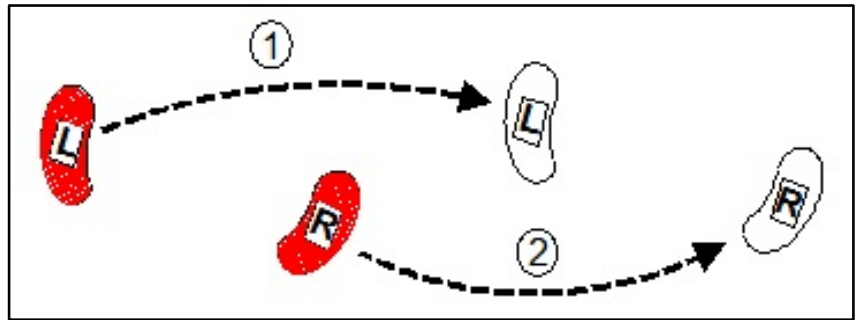

Figure 4. Crossover step

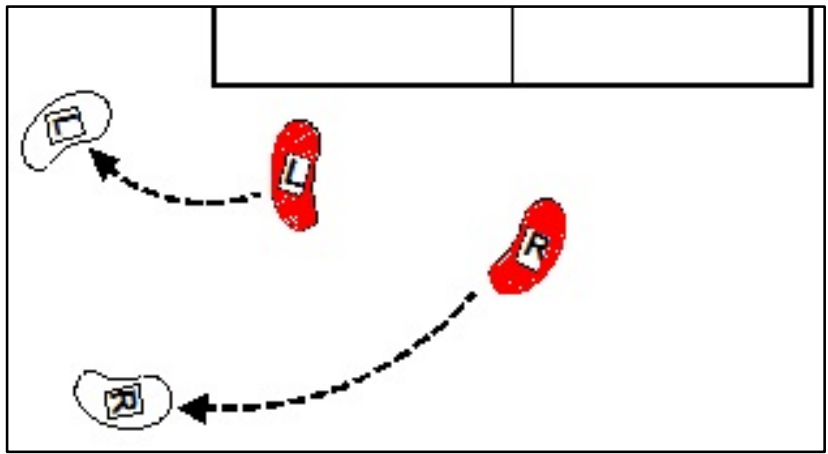

Figure 5. Pivot step

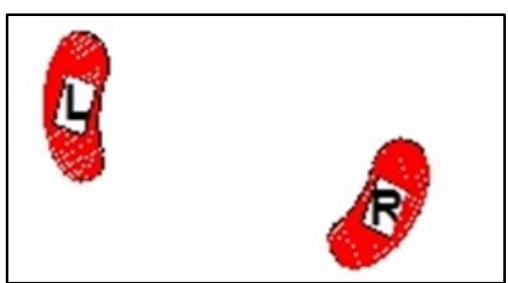

Figure 6. Shot without step

\section{Results}

A total of 18 matches $(M=9, W=9), 96$ sets $(M=$ $50, \mathrm{~W}=46), 1713$ rallies $(\mathrm{M}=902, \mathrm{~W}=811)$, and 7095 steps $(M=3322, \mathrm{~W}=3773)$ were considered. One way ANOVA showed significant differences ( $\mathrm{p} \leq$ $0.05^{*}, \mathrm{p} \leq 0.01^{* *}$ ) between $\mathrm{M}$ and $\mathrm{W}$ in the distribution of footwork types.

Table 1 shows the footwork distribution in $\mathrm{M}$ and W. M prefer to use one step (35.6\%, W: $21.9 \%)$, W prefer to hit the ball without performing any step (W: $40.2 \%$, M: $20.4 \%$ ), the chassé is equally used (M: $19.7 \%, \mathrm{~W}: 21.7 \%$ ), and the crossover is mainly used by M (11.1\%, W: 3.7\%). The pivot is mainly used by $\mathrm{M}$ (9.9\%, W: $7.8 \%)$, and $\mathrm{W}$ prefer the slide (4.9\%, M: $3.2 \%)$. 
Table 1.

Distribution of footwork types for men (M) and women (W) athletes $\left(p \leq 0.05^{*}, p \leq 0.01^{* *}\right)$

\begin{tabular}{ccc}
\hline .FOOTWORK & $\mathrm{M}$ & $\mathrm{W}$ \\
\hline one step** $^{*}$ & $35.6 \%$ & $21.9 \%$ \\
shot without step $^{* *}$ & $20.4 \%$ & $40.2 \%$ \\
chassé step $^{*}$ & $19.7 \%$ & $21.7 \%$ \\
crossover step** $^{*}$ & $11.1 \%$ & $3.7 \%$ \\
pivot step & $9.9 \%$ & $7.8 \%$ \\
slide step* & $3.2 \%$ & $4.9 \%$ \\
\hline Total & $100.0 \%$ & $100.0 \%$ \\
\hline
\end{tabular}

\section{Discussion}

The aim of this study was to compare footwork distributions in men (M) and women (W) elite table tennis competitions.

The results showed similarities between $\mathrm{M}$ and $\mathrm{W}$ in using chassé step which is a basic technique used to perform various sets of shots by making easy side movements in front of the table (Malagoli Lanzoni et al., 2014).

The pivot step is exclusively performed to play forehand shots from the backhand corner (Malagoli Lanzoni et al., 2014), and it is used by $\mathrm{M}$ and $\mathrm{W}$ with a similar distribution (9.9 and 7.8\%). Moreover, $\mathrm{M}$ and $\mathrm{W}$ players showed limited differences in using the slide step, consisting of sliding laterally first the foot corresponding to the direction of displacement, and then the other foot (Malagoli Lanzoni et al., 2014). W prefer to use this technique, compared to $\mathrm{M}$, showing limited differences $(\mathrm{p} \leq 0.05)$.

Instead, the main differences between $\mathrm{M}$ and $\mathrm{W}$ table tennis elite athletes with respect to footwork types concerned the One step, Shot without step, and crossover step $(\mathrm{p} \leq 0.01)$.

The one step is mainly used to answer the serve, and represents a key step for the first phases of the rally (Malagoli Lanzoni et al., 2014). It is mainly used by M to hit a close-to-the-net ball at the beginning of every rally. The difference to $\mathrm{W}$ could be connected with the use of long services performed in $\mathrm{W}$ competitions.

The shot without step category was strongly associated with $\mathrm{W}$ category. This demonstrates a less dynamic play concerning the footwork technique, connected with the use of backhand shots, which confirms previous literature about $\mathrm{W}$ footwork specific technique (Malagoli Lanzoni et al., 2013a).

The crossover allows the player to move for relatively long distances in the shortest time possible, and it is representative of the modern dynamic play (Malagoli Lanzoni et al., 2014). It is mainly used by M athletes and it is most likely linked to an offensive and risky style of play.

Hypothetical explanation of the different percentages of types of footwork can also be addressed considering constitutional differences, played systems, ball speed, placement of the balls, etc. It may be concluded, therefore, that the difference between $\mathrm{M}$ and $\mathrm{W}$ in elite table tennis competitions may have multifactorial origins, showing links with both technical and physical aspects.

This study should be extremely useful for physical trainers, performance analysts, and coaches, to design specific training sessions for $\mathrm{M}$ and $\mathrm{W}$ elite table tennis players, in order to improve footwork technique. Moreover, it should be used to plan specific physical trainings in order to prevent injuries in both categories planning different exercises.

In conclusion, future perspectives should be linked to the comparison of different categories of players, evaluating the connection with other variables (directions, shots, outcome, etc), and including quantitative analysis about footwork technique.

\section{References}

Djokić, Z. (2002). Structure of competitors' activities of top table tennis players. International Journal of Table Tennis Sciences, 4\&5, 74-90.

Drianovski, Y., \& Otcheva, G. (2002). Survey of the game styles of some of the best Asian players at the 12th World University Table Tennis Championships (Sofia, 1998). International Journal of Table Tennis Sciences, 4\&5, 3-9.

Fuchs, M., Liu, R., Malagoli Lanzoni, I., Munivrana, G., Straub, G., Tamaki, S., Yoshida, K., Zhang, H., \& Lames, M. (2018). Table Tennis Match Analysis: A Review. Journal of Sport Science, 36 (23), 2653-2662. doi: $10.1080 / 02640414.2018 .1450073$ 
Hughes, M. (1998). The application of notational analysis to racket sports. In Reilly, T., Hughes, M.D., Lees, A., Maynard, I. (Eds.). Science and Racket Sports II, (pp. 211-220). London: E. \& F.N. Spon.

Hughes, M., \& Barlett, R. (2002). The use of performance indicators in performance analysis, Journal of Sports Sciences, 20(10), 739-754. doi: $10.1080 / 026404102320675602$

Krippendorff, K. (2004). Content's analysis: An introduction to its methodology. Thousand Oaks, CA: Sage

Malagoli Lanzoni, I., Di Michele, R., \& Merni, F. (2012). Reliability of selected performance indicators in table tennis, International Journal of Table Tennis Sciences, 7, 62-65

Malagoli Lanzoni, I., Di Michele, R., \& Merni, F. (2013a). Distribution of stroke and footwork types in top-level men's and women's table tennis. In Peters, D.M., \& O'Donoghue (Eds). Performance Analysis of Sport IX, (pp. 168-173). Routledge: Taylor \& Francis.

Malagoli Lanzoni, I., Di Michele, R., \& Merni, F. (2013b). Technical and tactical performance of topclass senior, junior and cadet table tennis players, International Journal of Table Tennis Sciences, 8, 78-83

Malagoli Lanzoni, I., Di Michele, R., \& Merni, F. (2014). A notational analysis of shot characteristics in top-level table tennis players, European Journal of Sport Science, $14(4), \quad 309-17 . \quad$ doi: 10.1080/17461391.2013.819382

Malagoli Lanzoni, I., \& Lobietti, R. (2009). A pilot study to compare footwork techniques used in Table Tennis. In Hökelmann, A., \& Brummund, M. (eds.). Proceedings of the World Congress of Performance Analysis of Sport VIII. (pp. 58-62). Magdeburg: Otto-von-GuerickeUniversität Magdeburg.

Malagoli Lanzoni, I., Lobietti, R., \& Merni, F. (2007). Footwork techniques used in table tennis: a qualitative analysis. In M. Kondrič, \& G. Furjan Mandić (Eds.), Proceedings book of The 10 th Anniversary ITTF Sports Science Congress (pp. 401 - 408). Zagreb: University of Zagreb, Faculty of kinesiology; Croatian Table Tennis Association; International Table Tennis Federation.

Malagoli Lanzoni, I., Lobietti, R., \& Merni, F. (2010). Footwork in relationship with Strokes and Efficacy during the 29th Olympic Games table tennis final, International Journal of Table Tennis Sciences, 6, 60-63
Tepper, G. (2003). ITTF Level 1 Coaching Manual. Lousanne: International Table Tennis Federation

Zhang, H., Liu, W., Hu, J.J., \& Liu, R. (2014). Evaluation of elite table tennis players' technique effectiveness. Journal of Sports Sciences, 32 (1), 70-77. doi: 10.1080/02640414.2013.805885 